\title{
Staphylococcus lugdunensis infective endocarditis: description of 10 cases and analysis of native valve, prosthetic valve, and pacemaker lead endocarditis clinical profiles
}

\author{
I Anguera, A Del Río, J M Miró, X Matínez-Lacasa, F Marco, J R Gumá, G Quaglio, X Claramonte, \\ A Moreno, C A Mestres, E Mauri, M Azqueta, N Benito, C García-de la María, M Almela, M-J \\ Jiménez-Expósito, O Sued, E De Lazzari, J M Gatell, the Hospital Clinic Endocarditis Study Group
}

\begin{abstract}
Objective: To evaluate the incidence and the clinical and echocardiographic features of infective endocarditis (IE) caused by Staphylococcus lugdunensis and to identify the prognostic factors of surgery and mortality in this disease.

Design: Prospective cohort study.

Setting: Study at two centres (a tertiary care centre and a community hospital).

Patients: 10 patients with IE caused by S lugdunensis in 912 consecutive patients with IE between 1990 and 2003.

Methods: Prospective study of consecutive patients carried out by the multidisciplinary team for diagnosis and treatment of IE from the study institutions. English, French, and Spanish literature was searched by computer under the terms "endocarditis" and "Staphylococcus lugdunensis" published between 1989 and December 2003.

Main outcome measures: Patient characteristics, echocardiographic findings, required surgery, and prognostic factors of mortality in left sided cases of IE.

Results: 10 cases of IE caused by $S$ lugdunensis were identified at our institutions, representing $0.8 \%$ (four of 467), 1.5\% (two of 135), and 7.8\% (four of 51) of cases of native valve, prosthetic valve, and pacemaker lead endocarditis in the non-drug misusers. Native valve IE was present in four patients (two aortic, one mitral, and one pulmonary), prosthetic valve aortic IE in two patients, and pacemaker lead IE in the other four patients. All patients with left sided IE had serious complications (heart failure, periannular abscess formation, or shock) requiring surgery in $60 \%$ (three of five patients) of cases with an overall mortality rate of $80 \%$ (four of five patients). All patients with pacemaker IE underwent combined medical treatment and surgery, and mortality was $25 \%$ (one patient). In total 59 cases of IE caused by S lugdunensis were identified in a review of the literature. The combined analysis of these 69 cases showed that native valve IE (53 patients, $77 \%$ ) is characterised by mitral valve involvement and frequent complications such as heart failure, abscess formation, and embolism. Surgery was needed in $51 \%$ of cases and mortality was $42 \%$. Prosthetic valve endocarditis (nine of $60,13 \%$ ) predominated in the aortic position and was associated with abscess formation, required surgery, and high mortality (78\%). Pacemaker lead IE (seven of $69,10 \%$ ) is associated with a better prognosis when antibiotic treatment is combined with surgery.

Conclusions: $S$ lugdunensis IE is an uncommon cause of $\mathrm{IE}$, involving mainly native left sided valves, and it is characterised by an aggressive clinical course. Mortality in left sided native valve IE is high but the prognosis has improved in recent years. Surgery has improved survival in left sided IE and, therefore, early surgery should always be considered. Prosthetic valve $S$ lugdunensis IE carries an ominous prognosis.
\end{abstract}

Accepted 13 July 2004

S taphylococci species constitute a very important group of pathogens in infections of the cardiovascular system. The pathogenic significance and aggressiveness of these bacteria are well known. ${ }^{1}$ Staphylococcus lugdunensis was initially described in $1988^{2}$ as a separate species of coagulase negative staphylococci. The pathogenic potential of this microorganism has been clarified in a number of publications describing predominantly infections of the skin and soft tissues. ${ }^{3}$ In contrast to other staphylococcal endocarditis, infective endocarditis (IE) caused by S lugdunensis has seldom been reported in the past, and only case reports and brief case series have been published. ${ }^{4-43}$ In this report we describe our prospective experience with 10 new cases of IE caused by $S$ lugdunensis. In addition, we have extensively reviewed the literature with the goal of providing more insight into the incidence and the clinical and echocardiographic features of IE caused by $S$ lugdunensis, and the prognostic factors for requiring surgery and mortality in this disease.

\section{PATIENTS AND METHODS}

\section{Patient population}

This prospective study of consecutive patients was carried out by the multidisciplinary team for diagnosis and treatment of IE from the Hospital Clinic of Barcelona and the Infectious Diseases Unit from Mútua de Terrassa Hospital. The study institutions are a tertiary referral centre for complicated endocarditis and a community hospital, respectively, with a catchment area of 1050000 inhabitants. 
We prospectively identified and followed up all patients with IE admitted to both hospitals between 1990 and December 2003. Data were collected prospectively with a previously designed questionnaire that specified the clinical, microbiological, echocardiographic, treatment, and evolutive variables. ${ }^{44}$ Diagnosis of IE was established according to the Duke criteria. ${ }^{45}$ Results of two dimensional transthoracic echocardiography were routinely evaluated in all patients. Transoesophageal echocardiography was performed for suspected left sided endocarditis poorly defined by transthoracic echocardiography and for suspected intracardiac complications (complicated IE) and in all cases of prosthetic valve endocarditis.

\section{Microbiology}

All isolates of coagulase negative staphylococci are routinely sent for speciation at our institutions. S lugdunensis has been prospectively identified since 1996. All specimens of IE have been prospectively collected since 1990 and coagulase negative staphylococci were retrospectively investigated to identify all isolates of $S$ lugdunensis from the study institutions.

$S$ lugdunensis is a coagulase negative staphylococcus that can be identified with considerable accuracy according to its positive ornithine decarboxylase activity. All strains isolated were identified as $S$ lugdunensis on the basis of the following phenotypic characteristics: coagulase negative, pyrrolidonyl arylamidase positive, production of acetoine from glucose or pyruvate, and production of acid from trehalose, mannose, maltose, lactose, sucrose, and $\mathrm{N}$-acetyl-glucosamide. ${ }^{46} \mathrm{~A}$ commercial identification system (Api ID32 Staph, bioMérieux, Marcy l'Etoile, France) was used. Susceptibility to antimicrobial agents was determined by a disk diffusion method and confirmed by a broth microdilution method. In both cases, the recommendations stated in the National Committee for Clinical Laboratory Standards were followed. ${ }^{47}$

\section{Literature review}

The English, French, and Spanish language literature from 1988 to December 2003 was searched by computer (Medline) with the keywords "endocarditis" and "Staphylococcus lugdunensis".

\section{Statistical analysis}

Data were processed with the BMDP (1990) statistical package (BMDP Statistical Software, Inc, Los Angeles, California, USA). Clinical and echocardiographic variables for patients who required surgical treatment and for those with adverse outcome were analysed with Student's $t$ test for continuous variables and Fisher's exact test for categorical variables. The relation between covariates and requiring surgery or mortality was assessed by univariate analysis. Odds ratios (OR) were then determined with a logistic regression model. The OR and 95\% confidence intervals (CI) were calculated by StataCorp 1999 (Stata Statistical Software, release 6.0; Stata Corporation, College Station, Texas, USA). An adjusted analysis was performed with models constructed by multiple logistic regression analysis. Differences were considered significant when two sided p was less than 0.05 .

\section{RESULTS}

\section{Patient characteristics}

IE was diagnosed in 912 consecutive patients between 1990 and December 2003 in the study institutions; 259 cases of IE were in injection drug users and 653 in the general population. Ten cases of IE caused by $S$ lugdunensis were identified at the study institutions representing $1.1 \%$ of all cases of IE, and $0.8 \%, 1.5 \%$, and $7.8 \%$ of patients with native valve, prosthetic valve, and pacemaker lead endocarditis,
Table 1 Cases of infective endocarditis (IE) diagnosed from 1990 to 2003 at both study institutions

\begin{tabular}{lcc}
\hline & Overall & $\begin{array}{l}\text { Cases caused by } \\
\text { S lugdunensis }\end{array}$ \\
\hline Injection drug users & 259 & $0(0 \%)$ \\
General population & 653 & $10(1.5 \%)$ \\
Native valve IE & 467 & $4(0.8 \%)$ \\
Prosthetic valve IE & 135 & $2(1.5 \%)$ \\
Pacemaker lead IE & 51 & $4(7.8 \%)$ \\
Total & 912 & $10(1.1 \%)$ \\
\hline
\end{tabular}

respectively, in non-drug misusers (table 1). Table 2 summarises clinical variables and outcome of patients from the study institutions. Four patients had native valve IE (two aortic, one mitral, and one pulmonary), two had prosthetic valve aortic infection, and four had pacemaker lead endocarditis. All three patients with left sided native valve IE had serious complications (heart failure, periannular abscess formation, or shock) and two patients underwent surgery but died. Endocarditis was diagnosed in the remaining patient at necropsy. Prosthetic valve endocarditis was found in two patients, both in the aortic position and both complicated by periannular abscess formation; one patient underwent surgery and one patient died. All four patients with pacemaker lead endocarditis (three DDD and one VVI pacemaker) underwent combined medical treatment and surgery (complete removal of the pacing system) and mortality in this subgroup was $25 \%$.

Table 3 shows surgical rates and mortality according to the staphylococcus species identified among all cases of staphylococcal endocarditis diagnosed at the study institutions from 1990 to 2003. Rates of surgery for S lugdunensis IE were higher than for IE caused by Staphylococcus aureus in the general population $(70 \% v 36.9 \%$, OR $3.9,95 \%$ CI 1.1 to 14.7$)$ but not higher than for Staphylococcus epidermidis IE (70\% v 60\%, OR $1.5,95 \%$ CI 0.3 to 10.0$)$. Mortality in S lugdunensis IE was higher than in $S$ aureus IE in the general population $(50 \% \mathrm{v}$ $14.5 \%$, OR $5.9,95 \%$ CI 1.6 to 21.2 ) and in Sepidermidis IE (50\% v $20 \%$, OR $4,95 \%$ CI 1.1 to 14.9 ).

$S$ lugdunensis IE was identified in 59 cases of IE from 40 articles in a comprehensive review of the literature from 1988 (initial description) up to December 2003..$^{5-44}$ Table 4 shows the combined analysis of the reported cases in the literature and those from our institutions (69 cases). Native valve, prosthetic valve, and pacemaker IE accounted for $77 \%, 13 \%$, and $10 \%$ of cases from the overall population. Native valve IE (77\% of cases) was characterised by mitral valve involvement $(55 \%)$, acute onset $(54 \%)$, and frequent complications such as heart failure $(45 \%)$, periannular abscess formation (19\%), and peripheral embolism $(30 \%)$. Surgery was performed in $51 \%$ of patients; mortality was $42 \%$ in the overall group and $29 \%$ in patients who underwent surgery. In native valve disease, surgery was associated with improved survival (OR $3.2,95 \%$ CI 1.1 to 8.9 ). Prosthetic valve endocarditis ( $13 \%$ of cases) predominated in the aortic position (77\%) and was associated with extensive periannular tissue destruction (abscess formation in 66\% of cases). In this subgroup of patients, surgery was performed in $55 \%$ and mortality was $78 \%$. Pacemaker lead IE ( $10 \%$ of cases) was associated with a benign prognosis. Antibiotic treatment combined with surgery (extraction of all infected hardware) resulted in a mortality of $14 \%$.

\section{Antibiotic treatment}

Data on antibiotic susceptibility were obtained for $71 \%$ of patients; $84 \%$ of strains were penicillin susceptible, $94 \%$ were 
Table 2 Clinical characteristics, management, and outcome of patients from the two institutions

\begin{tabular}{|c|c|c|c|c|c|c|}
\hline $\begin{array}{l}\text { Age } \\
\text { (years) }\end{array}$ & Sex & Co-morbidity & $\begin{array}{l}\text { Valve involved, clinical } \\
\text { presentation }\end{array}$ & Complications & Surgery & Outcome \\
\hline 77 & $\mathrm{~F}$ & Liver cirrhosis, Le Veen shunt & $\begin{array}{l}\text { Native mitral, acute, no } \\
\text { echocardiography }\end{array}$ & Meningitis, CHF & No & Died in hospital \\
\hline 82 & $\mathrm{~F}$ & Ischaemic heart disease & $\begin{array}{l}\text { Native atrial, acute, veg } \\
12 \mathrm{~mm}\end{array}$ & $\begin{array}{l}\text { AMI, CHF, periannular } \\
\text { abscess }\end{array}$ & Yes & Died in hospital \\
\hline $68^{*}$ & $\mathrm{~F}$ & $\begin{array}{l}\text { DDD pacemaker } 7 \text { years, battery } \\
\text { replacement } 1 \text { year previously }\end{array}$ & $\begin{array}{l}\text { Pacemaker lead veg } \\
22 \mathrm{~mm} \text {, early onset }\end{array}$ & None & Yes & $\begin{array}{l}\text { Alive; relapse } 1 \text { year after initial } \\
\text { medical treatment: delayed } \\
\text { surgery (ET) }\end{array}$ \\
\hline 66 & M & DDD pacemaker 10 years previously & $\begin{array}{l}\text { Pacemaker lead veg } \\
23 \mathrm{~mm} \text {, late onset }\end{array}$ & Shock & Yes (CPB) & Died in hospital \\
\hline 78 & M & $\begin{array}{l}\text { DDD pacemaker } 5 \text { years, battery } \\
\text { replacement } 4 \text { months previously, } \\
\text { chronic pocket infection }\end{array}$ & $\begin{array}{l}\text { Pacemaker lead veg } \\
10 \mathrm{~mm} \text {, early onset }\end{array}$ & None & Yes (ET) & Alive \\
\hline 70 & M & Aortic valve surgery & $\begin{array}{l}\text { Aortic bioprosthesis, } \\
\text { acute, veg } 8 \mathrm{~mm}\end{array}$ & $\begin{array}{l}\text { Periannular abscess, } \\
\text { shock }\end{array}$ & Yes & Died in hospital \\
\hline 77 & M & Aortic valve surgery & $\begin{array}{l}\text { Aortic bioprosthesis, } \\
\text { chronic, no vegetation }\end{array}$ & Periannular abscess & No & Alive \\
\hline 43 & $\mathrm{~F}$ & Congenital pulmonary stenosis & $\begin{array}{l}\text { Native pulmonary, } \\
\text { acute, no veg }\end{array}$ & None & No & Alive \\
\hline 37 & M & None & $\begin{array}{l}\text { Native aortic, acute, } \\
\text { veg, no veg }\end{array}$ & $\begin{array}{l}\text { Peripheral embolism, } \\
\text { periannular abscess, } \\
\text { CHF, shock }\end{array}$ & Yes & Died in hospital \\
\hline 63 & M & $\begin{array}{l}\text { VVI pacemaker } 15 \text { years, battery } \\
\text { replacement } 2 \text { months previously, } \\
\text { chronic pocket infection }\end{array}$ & $\begin{array}{l}\text { Pacemaker lead veg } \\
8 \mathrm{~mm} \text {, early onset }\end{array}$ & None & Yes (ET) & Alive \\
\hline
\end{tabular}

*Reported previously in reference 24

Acute, duration of symptoms $<30$ days; $\mathrm{AMI}$, acute myocardial infarction; CHF, congestive heart failure; chronic, duration of symptoms $>30$ days; CPB, cardiopulmonary bypass; early onset, symptoms $<12$ months after surgical manipulation; ET, external traction; late onset, symptoms $>12$ months after surgical manipulation; F, female; $M$, male; Veg, vegetation.

methicillin susceptible, and all isolates were susceptible to vancomycin, aminoglycosides, and rifampin. Data on antibiotic treatment were obtained for $81 \%$ of patients and for the remaining patients antibiotic treatment was not specified. $\beta$ lactams alone (seven patients) or combined with other antibiotics (aminoglycosides in 27, rifampin in one, or cephalosporins in one) were administered to 36 patients. Vancomycin alone (five patients) or combined with other antibiotics (aminoglycosides in eight, rifampin in two, cephalosporins in four, or imipenem in one) was administered to 20 patients. Differences in mortality between the antibiotic regimens were not significant $(\beta$ lactams alone or combined with other antibiotics versus vancomycin alone or combined with other antibiotics, 52\% v 35.5\%, p = 0.35).

\section{Required surgery in left sided endocarditis}

Table 5 shows predictors of required surgery in left sided endocarditis in the univariate analysis. Younger patients (age $<50$ years), absence of significant co-morbidity, aortic valve involvement, and endocarditis complicated by formation of periannular abscesses were significantly associated with

Table 3 Surgical rates and mortality according to the staphylococcus species identified among all cases of staphylococcal endocarditis diagnosed at the study institutions (1990-2003)

\begin{tabular}{lrlc}
\hline & Total & Surgery & Mortality \\
\hline Staphylococcus aureus & 310 & $63(20.3 \%)$ & $22(7.1 \%)$ \\
Injected drug users & 172 & $12(7.0 \%)$ & $2(1.1 \%)$ \\
General population & 138 & $51(36.9 \%)$ & $20(14.5 \%)$ \\
Coagulase negative staphylococci & 98 & $53(54.0 \%)$ & $23(23.5 \%)$ \\
S epidermidis & 75 & $45(60.0 \%)$ & $15(20.0 \%)$ \\
S lugdunensis & 10 & $7(70.0 \%)^{*}$ & $5(50.0 \%) \dagger$ \\
S hominis & 6 & $1(16.6 \%)$ & $1(16.6 \%)$ \\
Other species & 7 & $2(40.0 \%)$ & $1(14.2 \%)$ \\
\hline
\end{tabular}

${ }^{*} \mathrm{p}<0.04$ versus $S$ aureus in the general population and not significant versus $S$ epidermidis; $\uparrow p<0.01$ versus $S$ aureus in the general population and $p<0.04$ versus $S$ epidermidis. increased need for surgery. There was a trend towards increased use of surgery in multivalvar IE and when the clinical course was complicated with heart failure (table 5). All the variables in the univariate analysis with $\mathrm{p}<0.1$ were considered for multivariate analysis. Periannular abscess formation (OR 5.4, 95\% CI 1.2 to 23.4, p = 0.02) and younger age (OR $4.9,95 \%$ CI 1.3 to $18.9, \mathrm{p}=0.01$ ) were found to be independent prognostic factors for surgery.

\section{Prognostic factors of mortality in left sided endocarditis}

Table 6 shows predictors of mortality in left sided endocarditis in the univariate analysis. Age $>50$ years, cases reported before 1995, and absence of surgery were significantly associated with increased mortality. Patients who did not undergo surgery had a relative risk of mortality 2.9 times (95\% CI 1.0 to $8.7, p=0.05$ ) higher than those who were operated on. All the variables in the univariate analysis with $\mathrm{p}<0.1$ were considered for multivariate analysis. A diagnosis before 1995 (year of publication) (OR 3.3, 95\% CI 1.1 to $11.4, p=0.05$ ) was the only independent prognostic factor for mortality.

\section{DISCUSSION}

The various species of coagulase negative staphylococci constitute the major component of the saprophyte flora in humans. Although multiple species of coagulase negative staphylococci have been described, only a minority infect humans but they are the leading cause of prosthetic material infection. ${ }^{1}$ In 1988, a new genomic species of coagulase negative staphylococci was reported by Freney et al. ${ }^{2}$ This species is readily differentiated from other coagulase negative staphylococci by the production of ornithine decarboxylase and pyrrolidonyl arylamidases. S lugdunensis can bind vitronectin and fibrinogen to extracellular matrix proteins and may be misidentified as $S$ aureus because some isolates produce clumping factor, resulting in positive slide coagulase or latex agglutination tests. This may explain the disparity between $S$ lugdunensis isolates in coagulase negative staphylococci 
Table 4 Overall clinical characteristics of 69 cases ( 10 from the two study institutions and 59 from the literature)

\begin{tabular}{llll}
\hline Clinical characteristics & $\begin{array}{l}\text { Native valve } \\
\text { (n=53) }\end{array}$ & $\begin{array}{l}\text { Prosthetic valve } \\
\text { (n=9) }\end{array}$ & $\begin{array}{l}\text { Pacemaker lead* } \\
\text { (n=7) }\end{array}$ \\
\hline Mean age (years) & 55 & 63 & 63 \\
Age $<50$ years & $36 \%$ & $11 \%$ & $14 \%$ \\
Male sex & $49 \%$ & $33 \%$ & $14 \%$ \\
Published before 1995 & $36 \%$ & $77 \%$ & $0 \%$ \\
Previous heart disease† & $38 \%$ & $100 \%$ & $100 \%$ \\
Co-morbidity & $30 \%$ & $22 \%$ & $14 \%$ \\
Known source of infection§ & $45 \%$ & $33 \%$ & $71 \%$ \\
Injection drug users & $0 \%$ & $0 \%$ & $0 \%$ \\
Location & & & \\
Mitral valve & $55 \%$ & $11 \%$ & $0 \%$ \\
Aortic valve & $28 \%$ & $77 \%$ & $0 \%$ \\
Tricuspid valve & $0 \%$ & $0 \%$ & $0 \%$ \\
Pulmonary valve & $4 \%$ & $0 \%$ & $100 \%$ \\
Pacemaker lead & $0 \%$ & $0 \%$ & $0 \%$ \\
Multivalvar & $13 \%$ & $11 \%$ & $57 \%$ \\
Acute onset (<30 days) & $54 \%$ & $11 \%$ & $14 \%$ \\
Complications & $60 \%$ & $77 \%$ & $0 \%$ \\
Heart failure & $45 \%$ & $22 \%$ & $0 \%$ \\
Periannular abscess & $19 \%$ & $66 \%$ & $14 \%$ \\
Embolisation & $30 \%$ & $11 \%$ & $100 \%$ \\
Vegetation on echocardiogram & $85 \%$ & $22 \%$ & $100 \%$ \\
Surgery & $51 \%$ & $55 \%$ & $14 \%$ \\
Death & $42 \%$ & $78 \%$ & $14 \%$ \\
Antibiotic + surgery & $29 \%$ & $80 \%$ & $0 \%$ \\
Antibiotic alone (no surgery) & $57 \%$ & $75 \%$ & \\
\hline
\end{tabular}

*Pacemaker (6), implantable cardioverter defibrillator (1); taortic (7) or mitral (1) prosthesis, rheumatic valve (6), bicuspid aortic valve (3), mitral regurgitation (6), pacemaker (6), ischaemic heart disease (2), pulmonary stenosis (1), implantable defibrillator (1); †AIDS (1), congestive heart failure (6), end stage renal disease (3), liver cirrhosis (2), malignancy (2), rheumatoid arthritis (2), diabetes mellitus (1), lymphoma (1), renal transplant (1); §cutaneous infection (14), arteriovenous fistula or graft (5), vasectomy (4), arthritis (2), dental abscess (1), scrotal ulceration (1), coronary angiography (1) or angioplasty (1), percutaneous valvoplasty (1), others (2); $9 p<0.04$ versus antibiotic + surgery; ${ }^{* *}$ not significant versus antibiotic + surgery.

endocarditis, which has been reported to be between $0 \%^{8}$ and $44 \% .^{32}$ It may also explain why endocarditis caused by coagulase negative staphylococci is associated with a subacute and indolent infection with few complications in some reports ${ }^{48}$ and with an aggressive infection with valve dysfunction, heart failure, and high mortality in others. ${ }^{49}$

\begin{tabular}{|c|c|c|c|c|c|}
\hline Variable & & $\mathrm{n}$ & $\begin{array}{l}\text { Surgery } \\
\text { required }\end{array}$ & OR (95\% Cl) & p Value \\
\hline Age & $\begin{array}{l}>50 \text { years } \\
<50 \text { years }\end{array}$ & $\begin{array}{l}38 \\
19\end{array}$ & $\begin{array}{l}17(45 \%) \\
15(79 \%)\end{array}$ & $\begin{array}{l}1 \\
4.6(1.2 \text { to } 16.5)\end{array}$ & 0.01 \\
\hline Sex & $\begin{array}{l}\mathrm{F} \\
\mathrm{M}\end{array}$ & $\begin{array}{l}25 \\
32\end{array}$ & $\begin{array}{l}15(60 \%) \\
17(53 \%)\end{array}$ & 1 (0.7 (0.2 to 2.2$)$ & 0.6 \\
\hline Previous heart disease ${ }^{*}$ & $\begin{array}{l}\text { No } \\
\text { Yes }\end{array}$ & $\begin{array}{l}32 \\
25\end{array}$ & $\begin{array}{l}17(53 \%) \\
15(60 \%)\end{array}$ & $1.3(0.4$ to 3.8$)$ & 0.6 \\
\hline Co-morbidity* & $\begin{array}{l}\text { No } \\
\text { Yes }\end{array}$ & $\begin{array}{l}41 \\
16\end{array}$ & $\begin{array}{r}27(66 \%) \\
5(31 \%)\end{array}$ & $0.2(0.07$ to 0.8$)$ & 0.02 \\
\hline Source of infection* & $\begin{array}{l}\text { Unknown } \\
\text { Known }\end{array}$ & $\begin{array}{l}33 \\
24\end{array}$ & $\begin{array}{l}19(57 \%) \\
13(54 \%)\end{array}$ & $0.9(0.3$ to 2.5$)$ & 0.8 \\
\hline Endocarditic valve & $\begin{array}{l}\text { Prosthetic } \\
\text { Native }\end{array}$ & $\begin{array}{r}8 \\
49\end{array}$ & $\begin{array}{r}5(62 \%) \\
27(55 \%)\end{array}$ & $0.7(0.1$ to 3.4$)$ & 0.7 \\
\hline Valve involved & $\begin{array}{l}\text { Mitral } \\
\text { Aortict }\end{array}$ & $\begin{array}{l}28 \\
29\end{array}$ & $\begin{array}{l}10(36 \%) \\
22(76 \%)\end{array}$ & $5.6(1.8$ to 17.8$)$ & 0.003 \\
\hline Number of valves & $\begin{array}{l}1 \\
>1\end{array}$ & $\begin{array}{r}49 \\
8\end{array}$ & $\begin{array}{r}26(53 \%) \\
6(75 \%)\end{array}$ & $2.6(0.5$ to 14.4$)$ & 0.2 \\
\hline Acute onset ( $<30$ days) & $\begin{array}{l}\text { No } \\
\text { Yes }\end{array}$ & $\begin{array}{l}10 \\
28\end{array}$ & $\begin{array}{r}6(60 \%) \\
19(68 \%)\end{array}$ & $1.4(0.3$ to 6.2$)$ & 0.6 \\
\hline Embolisation & $\begin{array}{l}\text { No } \\
\text { Yes }\end{array}$ & $\begin{array}{l}29 \\
17\end{array}$ & $\begin{array}{l}16(55 \%) \\
12(70 \%)\end{array}$ & $1.9(0.5$ to 6.9$)$ & 0.3 \\
\hline Diagnosisł & $\begin{array}{l}<1995 \\
>1995\end{array}$ & $\begin{array}{l}22 \\
35\end{array}$ & $\begin{array}{l}11(50 \%) \\
21(60 \%)\end{array}$ & $1.5(0.5$ to 4.4$)$ & 0.5 \\
\hline Periannular abscess & $\begin{array}{l}\text { No } \\
\text { Yes }\end{array}$ & $\begin{array}{l}41 \\
16\end{array}$ & $\begin{array}{l}19(46 \%) \\
13(81 \%)\end{array}$ & $\begin{array}{l}1 \\
5.0 \text { (1.2 to } 20.3)\end{array}$ & 0.02 \\
\hline Heart failure & $\begin{array}{l}\text { No } \\
\text { Yes }\end{array}$ & $\begin{array}{l}20 \\
26\end{array}$ & $\begin{array}{l}10(50 \%) \\
18(69 \%)\end{array}$ & $\begin{array}{l}1 \\
2.2(0.7 \text { to } 7.5)\end{array}$ & 0.2 \\
\hline
\end{tabular}

*Detailed in table 4; tincludes aortic valve involvement also in multivalvar infection; łyear of publication. 


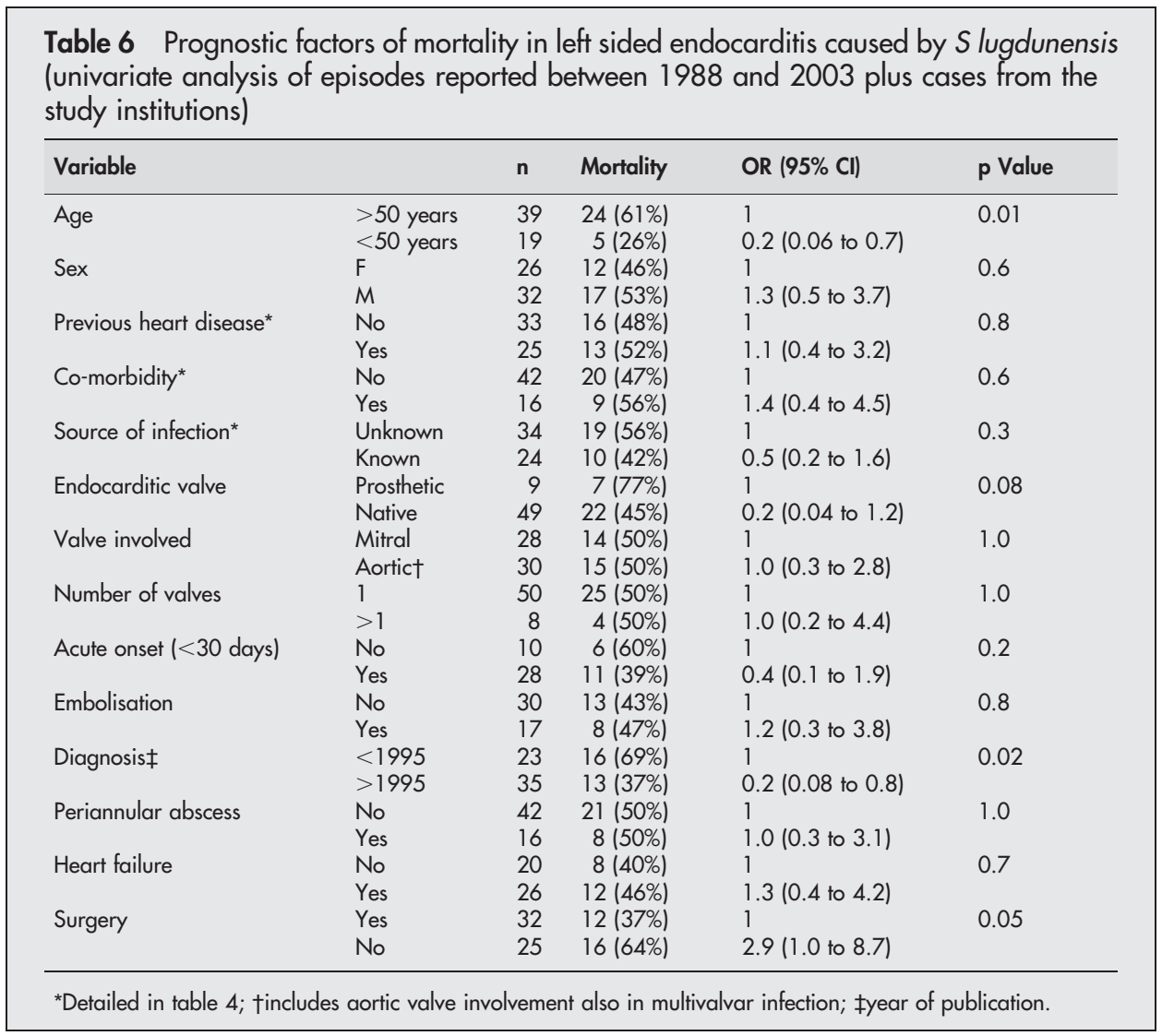

\section{Characteristics of $S$ lugdunensis endocarditis}

$S$ lugdunensis is a coagulase negative staphylococcus infecting predominantly the skin and soft tissue and is only occasionally responsible for IE. ${ }^{3}$ Owing to the prospective design of this study, we calculated that $S$ lugdunensis IE accounted for only $1.1 \%$ of all cases of IE diagnosed at the study institutions, and $0.8 \%, 1.5 \%$, and $7.8 \%$ cases of native valve, prosthetic valve, and pacemaker endocarditis, respectively. The majority of patients acquired the infection in the community and a site of entry was not identified for some patients. Sources of infection have been reported to be dental abscesses, cutaneous infection, infected vascular accesses, infected pacemakers, vasectomies, and others (table 4).

Some clinical determinants of $S$ lugdunensis infection have been reported previously and were confirmed in the present investigation. In contrast to the indolent presentation characteristic of native valve endocarditis caused by other coagulase negative staphylococci, S lugdunensis causes valve destruction and multiple complications similar to those in endocarditis caused by $S$ aureus. S lugdunensis IE is characterised by a poor response to conventional antimicrobial treatment, with important valvar destruction, myocardial abscess formation, high peripheral embolic rate, and high mortality, including cases referred for surgical treatment. The majority of cases of IE caused by $S$ lugdunensis involve native valves (77\%), whereas other coagulase negative staphylococci (mainly $S$ epidermidis) infect the prosthetic valve. Mitral and aortic valve infection is often reported and in some cases there is multivalvar endocarditis. Severe complications such as heart failure and the need for valve replacement were present in $45 \%$ and $51 \%$ of patients, respectively, compared with $30-38 \%$ and $27-34 \%$ for other coagulase negative staphylococci. In line with these data, surgical rates of $S$ lugdunensis IE from all cases of staphylococcal endocarditis diagnosed at the study institutions were higher than surgical rates for $S$ aureus IE (table 3 ). Overall mortality is in the range of $50 \%$, which is considerably higher than the mortality reported for other coagulase negative staphylococci (16\%). ${ }^{1}$ As table 3 shows, we observed higher mortality for $S$ lugdunensis IE than for $S$ aureus and $S$ epidermidis IE. The higher surgical rates and mortality of $S$ lugdunensis IE are probably due to the intrinsic virulence of this particular organism. Endocarditis affected the prosthetic valve in only $13 \%$ of all cases but this type of infection is associated with the highest complication rates and mortality. Surgery did not reduce mortality in this subgroup of patients, probably because of advanced periannular destruction and the low number of patients.

Pacemaker lead endocarditis constitutes another subgroup in $S$ lugdunensis IE that has not been previously characterised. Only seven cases have been reported, three from the literature review ${ }^{22} 26$ and four from the present study. Pacemaker lead endocarditis accounted for $7.8 \%$ of all cases of IE from the study institutions, and when the entire pacing system was extracted mortality was very low. Mortality from electrode lead $S$ lugdunensis IE is not different from mortality caused by the general series of pacemaker lead endocarditis. ${ }^{50}$

\section{Antibiotic susceptibility and medical treatment}

We observed no differences in terms of mortality between the treatment options. Mortality rates did not differ between treatment with $\beta$ lactams alone or combined with other antibiotics and treatment with vancomycin alone or in combination, or between monotherapy and combined treatment. There is no specific pattern of susceptibility to antibiotics in endocarditis caused by $S$ lugdunensis. This makes the choice of antibiotics dependent on antibiotic susceptibility tests. However, the majority of strains were penicillin and methicillin susceptible. Despite the microorganism's susceptibility in vitro, an antibiotic alone is seldom successful and the majority of patients need surgery during the active phase of the disease. S lugdunensis and $S$ aureus share similar morphology and both species produce 
clumping factor (bound coagulase) resulting in positive slide coagulase and latex agglutination test. Negative tube coagulase tests and positive pyrrolidonyl arylamidase, ornithine decarboxylase, and mannitol fermentation tests distinguish $S$ lugdunensis from other clumping factor producing staphylococcus species. Prompt speciation can lead to earlier recognition of $S$ lugdunensis and earlier suspicion of IE and, therefore, enables earlier medical treatment and surgery.

\section{Surgery}

The available clinical data suggest that $S$ lugdunensis is an aggressive pathogen. Frequent and severe in-hospital complications and high mortality characterise $S$ lugdunensis IE even when surgery is performed early in the course of the disease. Most patients had a short duration of symptoms, usually for less than three weeks, and there was often gross valvar destruction with abscess formation requiring valve replacement (table 4 ). In our review, $51 \%$ of patients required surgical intervention for native valve endocarditis, 55\% for prosthetic infection, and $100 \%$ for infected pacemakers. Some subgroups of patients underwent surgery for left sided endocarditis to reduce mortality; $57 \%$ of patients who did not undergo surgery died compared with $29 \%$ of patients who did have surgery (table 4). Deaths were common in the older group, who were more likely treated conservatively. Absence of significant co-morbidity, aortic valve involvement, and endocarditis complicated by formation of periannular abscess were significantly associated with increased use of surgery; most deaths occurred in the earlier reports.

\section{Prognosis}

Mortality in IE caused by $S$ lugdunensis is high, both for native $(42 \%)$ and prosthetic $(78 \%)$ valves, although it has been shown to have decreased in recent years (year of publication after 1995). These figures are closer to those reported for IE caused by other aggressive pathogens such as $S$ aureus, ${ }^{51}$ group B streptococci, ${ }^{52}$ or pneumococci ${ }^{53}$ and are far from the $6 \%$ mortality in non-aggressive endocarditis caused by viridans group streptococci. ${ }^{54}$ Cases reported before 1995 and older patients (age $>50$ years) were significantly associated with increased mortality. Patients with left sided involvement who did not undergo an operation had a relative risk of mortality 2.9 times higher than those operated on. Although the proportion of patients referred for surgery for left sided endocarditis did not differ substantially before and after 1995 (50\% $\vee 60 \%$, respectively), mortality decreased from $69 \%$ to $37 \%$ during both time periods. Perhaps increased recognition of this pathogen and its virulence has led to earlier and more aggressive management including surgery. Age and status of co-morbidities may have had an important role in reducing mortality because younger patients without significant co-morbidities had undergone more surgical procedures with decreased mortality. Absolute numbers of cases of prosthetic valve endocarditis caused by this organism are very low, thus precluding analysis of factors influencing mortality in prosthetic valve endocarditis. Surgical treatment was not more often required for prosthetic valve endocarditis than for native valves and surgery did not statistically reduce mortality in prosthetic valve endocarditis. This is presumed to be due to differences in baseline characteristics of patients, differences in associated complications, the aggressive nature of the infection, and the low number of patients.

\section{Study limitations}

This study has some limitations. There is a potentially significant bias because, although the study was based on a prospective analysis of cases at our institutions, the main source of information was cases reported in the literature. The severity of $S$ lugdunensis endocarditis may appear higher because cases with a complicated course and poor outcome are more likely to be published. Subgroup analysis did not show a reduction in mortality with the use of surgery in certain subgroups of patients because of the retrospective nature of the study, and there is a clear bias in selection of the mode of treatment. A type II error due to the low number of patients is probably the cause of this lack of benefit of surgery in some subgroup of patients. However, this is the largest analysis ever reported of IE caused by $S$ lugdunensis.

\section{Conclusion}

$S$ lugdunensis IE is an uncommon cause of IE involving mainly native left sided valves. Despite the retrospective and nonrandomised nature of the study and the potential selection bias, we conclude that $S$ lugdunensis IE has an aggressive course with high rates of severe in-hospital complications. Therefore, all coagulase negative staphylococci should be identified by species in all cases of complicated IE to allow early identification of $S$ lugdunensis. Mortality in left sided native valve endocarditis is high but the prognosis has improved in recent years. Surgery improved survival in left sided IE and, therefore, early surgery should always be considered. Prosthetic valve endocarditis due to S lugdunensis carries an ominous prognosis.

\section{ACKNOWLEDGMENTS}

Thanks to María Antonia Rodríguez Jové for her technical assistance. This study was supported in part by the Red Española de Investigación en Patología Infecciosa (V-2003-REDC14A-O) and the Fundación Privada Máximo Soriano Jiménez, Barcelona, Spain. Dr J M Miró was a recipient of a research grant from the Institut $\mathrm{d}$ 'Investigacions Biomèdiques August Pi i Sunyer (IDIBAPS), Barcelona, Spain.

\section{Authors' affiliations \\ I Anguera, J R Gumá, Department of Cardiology, Corporació Parc Taulí, Hospital de Sabadell, Sabadell, Spain \\ A Del Río, J M Miró, G Quaglio, X Claramonte, A Moreno, N Benito, M-J Jiménez-Expósito, O Sued, J M Gatell, Service of Infectious Diseases, Institut Clínic d'Infeccions i d'Immunologia, University of Barcelona, Barcelona, Spain \\ X Matínez-Lacasa, E Mauri, Infectious Diseases Unit, Hospital Mútua de Terrassa, Barcelona, Spain \\ F Marco, C García-de la María, M Almela, Service of Microbiology, Institut Clínic d'Infeccions i d'Immunologia, University of Barcelona C A Mestres, Department of Cardiovascular Surgery, University of Barcelona \\ M Azqueta, Department of Cardiology, University of Barcelona E De Lazzari, Epidemiology and Biostatistics Unit, Institut $\mathrm{d}^{\prime}$ Investigacions Biomèdiques August Pi i Sunyer, Hospital Clinic, University of Barcelona}

\section{APPENDIX}

Members of the Hospital Clinic Endocarditis Study Group of the Institut d'Investigacions Biomèdiques August Pi i SunyerHospital Clinic, University of Barcelona, Barcelona, Spain: Miró JM, del Río A, de Benito N, Jiménez-Expósito MJ, Sued O, Claramonte X, Díaz ME, Moreno A, Gatell JM (Division of Infectious Diseases); Marco F, García de la María C, Armero Y, Almela M, Jiménez de Anta MT (Department of Microbiology); Paré JC, Azqueta M (Department of Cardiology); Mestres CA, Ninot S, Cartaña R, Pomar JL (Department of Surgery); and Pérez N, Ramírez J, Ribalta T (Department of Pathology).

\section{REFERENCES}

1 Whitener C, Caputo GM, Weitekamp MR, et al. Endocarditis due to coagulase-negative staphylococci: microbiologic, epidemiologic and clinical considerations. Infect Dis Clin North Am 1993;7:81-96.

2 Freney J, Brun Y, Bes $M$, et al. Staphylococcus lugdunensis sp. nov. and Staphylococcus schleiferi sp. nov., two species from human clinical species. Int J Syst Bacteriol 1988;38:168-72. 
3 Herchline TE, Ayers L W. Occurrence of Staphylococcus lugdunensis in consecutive clinical cultures and relationship of isolation to infection. J Clin Microbiol 1991;29:419-21.

4 Smyth EG, Wright DE, Marples RR. New type of staphylococcal endocarditis [letter]. J Clin Pathol 1988:41:809-10.

5 Etienne J, Pangon B, Leport C, et al. Saphylococcus lugdunensis endocarditis [letter]. Lancet 1989;i:390.

6 Fleurette J, Bes M, Brun Y, et al. Clinical isolates of Staphylococcus lugdunensis and S. schleiferi: bacteriological characteristics and susceptibility to antimicrobial agents, Res Microbiol 1989;140:107-18.

7 Walsh B, Mounsey JP. Staphylococcus lugdunensis and endocarditis [letter] J Clin Pathol 1990;43:171.

8 Barker KF, O'Driscoll JC, Bhargava A. Staphylococcus lugdunensis. J Clin Pathol 1991;44:873-4.

9 Cormican MG, El Bouri K, Corbett-Feeney G, et al. Staphylococcus lugdunensis endocarditis [letter]. J Infect 1992;24:335-6.

10 Sheppard $M$, Jankowski S. Staphylococcus lugdunensis endocarditis [letter]. J Infect 1992;25:116-7.

11 Shuttleworth R, Colby WD. Staphylococcus lugdunensis endocarditis. J Clin Microbiol 1992;30:1948-52.

12 Schonheyder HC, Hansen VK, Asschenfeldt P, et al. Staphylococcus lugdunensis: an important cause of endocarditis. A case report. APMIS 1993;101:802-4.

13 Vandenesch F, Etienne J, Reverdy ME, et al. Endocarditis due to Staphylococcus lugdunensis: report of 11 cases and review. Clin Infect Dis 1993;17:871-6.

14 Breen JD, Karchmer AW. Usefulness of pulsed-field gel electrophoresis in confirming endocarditis due to Staphylococcus lugdunensis. Clin Infect Dis 1994;19:985-6.

15 Costello R, Miquel M, Gastaut JA, et al. [Native valve Staphylococcus lugdunensis endocarditis in a patient with lymphoma]. Ann Med Interne (Paris) 1995; 146:369

16 Kralovic SM, Melin-Aldana H, Smith KK, et al. Staphylococcus lugdunensis endocarditis after tooth extraction. Clin Infect Dis 1995;20:715-6.

17 Dupont C, Turner L, Pinguet $O$, et al. [Staphylococcus lugdunensis endocarditis: a new case]. Ann Med Interne (Paris) 1996;147:374-5.

18 Koh TW, Brecker SJ, Layton CA. Successful treatment of Staphylococcus lugdunensis endocarditis complicated by multiple emboli: a case report and review of the literature. Int J Cardiol 1996;55:193-7.

19 Lessing MP, Crook DW, Bowler IC, et al. Native-valve endocarditis caused by Staphylococcus lugdunensis. Q J Med 1996:89:855-8.

20 De Hondt G, leven M, Vandermersch C, et al. Destructive endocarditis caused by Staphylococcus lugdunensis: case report and review of the literature. Acta Clin Belg 1997; 52:27-30.

21 Waterer G, Wilson R, Dimmitt S, et al. Staphylococcus lugdunensis endocarditis. Aust N Z J Med 1997;27:84-5.

22 Celard M, Lelievre $\mathrm{H}$, Obadia JF, et al. Long-standing bacteremia and endocarditis caused by Staphylococcus lugdunensis in a patient with an implantable cardioverter defibrillator. Clin Microbiol Infect 1997;3:387-8.

23 Laguno M, Miro O, Font C, et al. Pacemaker-related endocarditis: report of 7 cases and review of the literature. Cardiology 1998;90:244-8.

24 Llinares P, Moure R, Cerqueiro J, et al. [Endocarditis caused by Staphylococcus lugdunensis: hospital incidence]. Enferm Infecc Microbiol Clin 1998;16:233-6.

25 Sanchis-Bayarri Vaillant V, Llucian Rambla R, Sanchis-Bayarri Bernal V. [A study of 7 cases of Staphylococcus lugdunensis infection]. An Med Interna 1999;16:361-2.

26 Bobin S, Durand-Dubief A, Bouhour D, et al. Pacemaker endocarditis due to Staphylococcus lugdunensis: report of two cases. Clin Infect Dis 1999;28:404-5.

27 Burgert SJ, LaRocco MT, Wilansky S. Destructive native valve endocarditis caused by Staphylococcus lugdunensis. South Med J 1999:92:812-4.

28 Fervenza FC, Contreras GE, Garratt KN, et al. Staphylococcus lugdunensis endocarditis: a complication of vasectomy? Mayo Clin Proc 1999;74:1227-30.

29 Kamaraju S, Nelson K, Williams DN, et al. Staphylococcus lugdunensis pulmonary valve endocarditis in a patient on chronic hemodialysis. Am J Nephrol 1999; 19:605-8.
30 Wasserman E, Lombard L, Walzl G. Staphylococcus lugdunensis endocarditis in a young, previously healthy female. Eur J Clin Microbiol Infect Dis 1999; 18:289-91.

31 Kragsbjerg P, Bomfim-Loogna J, Törnqvist E, et al. Development of antimicrobial resistance in Staphylococcus lugdunensis during treatmentreport of a case of bacterial arthritis, vertebral osteomyelitis and infective endocarditis. Clin Microbiol Infect 2000;6:496-9.

32 Patel R, Piper KE, Rouse MS, et al. Frequency of isolation of Staphylococcus lugdunensis among staphylococcal isolates causing endocarditis: a 20-year experience. J Clin Microbiol 2000;38:4262-3.

33 Polenakovik H, Herchline T, Bacheller C, et al. Staphylococcus lugdunensis endocarditis after angiography. Mayo Clin Proc 2000;75:656-7.

34 Renzulli A, Della Corte A, Torella $M$, et al. Mitral and aortic valve endocarditis due to Staphylococcus lugdunensis. Tex Heart Inst J 2000;27:67-9.

35 Teong HH, Leo YS, Wong SY, et al. Case report of Staphylococcus lugdunensis native valve endocarditis and review of the literature. Ann Acad Med Singapore 2000;29:673-7.

36 Sanchez A, Martinez I, Sanz F, et al. Aggressive acute endocarditis caused by Staphylococcus lugdunensis complicated with multiple cerebral septic emboli. Enferm Infecc Microbiol Clin 2000;10:526-7.

37 Farrag N, Lee P, Gunney R, et al. Staphylococcus lugdunensis endocarditis. Postgrad Med J 2001;906:259-60.

38 Jones RM, Jackson MA, Ong C, et al. Endocarditis caused by Staphylococcus lugdunensis. Pediatr Infect Dis J 2002;3:265-8.

39 Wächtler $M$, Strobel $E$, Koch $U$, et al. Native mitral valve endocarditis caused by Staphylococcus lugdunensis in a 22-year-old woman. Infection 2002;4:251-3

40 Sotutu V, Carapetis J, Wilkinson J, et al. The "surreptitious Staphylococcus": Staphylococcus lugdunensis endocarditis in a child. Pediatr Infect Dis $J$ 2002;10:984-6.

41 Garcia Fernandez FJ, Berion Reyero J, Ruiz Quevedo V, et al. [Staphylococcus lugdunensis endocarditis. Case report and review of the literature]. Rev Clin Esp 2003;2:98-9.

42 Seenivasan MH, Yu VL. Staphylococcus lugdunensis endocarditis: the hidden peril of coagulase-negative staphylococcus in blood cultures. Eur J Clin Microbiol Infect Dis 2003;8:489-91.

43 Rodriguez-Gascon M, Roig P, Montagud JB, et al. [Acute Staphylococcus lugdunensis endocarditis with septic cerebral and pulmonary emboli, showing favorable evolution]. Enferm Infecc Microbiol Clin 2003:8:465-7.

44 Losa JE, Miro JM, Del Rio A, et al. Infective endocarditis not related to intravenous drug abuse in HIV-1-infected patients: report of eight cases and review of the literature. Clin Microbiol Infect 2003;1:45-54.

45 Durack DT, Lukes AS, Bright DK, and the Duke Endocarditis Service. New criteria for diagnosis of infective endocarditis: utilization of specific echocardiographic findings. Am J Med 1994;96:200-9.

46 Kloos WE, Bannerman TL. Staphylococcus and micrococcus. In: Murray PR, Baron EJ, Pfaller MA, et al, eds. Manual of clinical microbiology. Washington: American Society of Microbiology, 1999:264-82.

47 National Committee for Clinical Laboratory Standards. Performance standards for antimicrobial susceptibility testing: eleventh informational supplement, NCCLS document M100-S11. Wayne: National Committee for Clinical Laboratory Standards, 2001.

48 Arber N, Militianu A, Ben-Yehuda A, et al. Native valve Staphylococcus epidermidis endocarditis: report of seven cases and review of the literature. Am J Med 1991;90:758-62.

49 Caputo GM, Archer GL, Calderwood SB, et al. Native valve endocarditis due to coagulase negative staphylococci: clinical and microbiologic features. Am J Med 1987:83:619-25.

50 Del Rio A, Anguera I, Miro JM, et al. Surgical treatment of pacemaker and defibrillator lead endocarditis: the impact of electrode lead extraction on outcome. Chest 2003;124:1451-9.

51 Karchmer AW. Staphylococcal endocarditis. In: Kaye D, ed. Infective endocarditis, 2nd edn. New York: Raven Press, 1992:225-50.

52 Rollan MJ, San Roman JA, Vilacosta I, et al. Clinical profile of Streptococcus agalactiae native valve endocarditis. Am Heart J 2003;146:1095-8.

53 Martinez E, Miro JM, Almirante B, et al. Effect of penicillin resistance of Streptococcus pneumoniae on the presentation, prognosis, and treatment of pneumococcal endocarditis in adults. Clin Infect Dis 2002;35:130-9.

54 Bayliss R, Clarke C, Oakley CM, et al. The microbiology and pathogenesis of infective endocarditis. Br Heart J 1983;50:513-9. 